\title{
Toxicidade do extrato etanólico de Magonia pubescens sobre larvas de Aedes aegypti
}

\author{
Toxicity of the ethanol extract of Magoniapubescens on larvae Aedes aegypti
}

\author{
Walquíria Arruda ${ }^{1}$, Gláucia Maria Cavasin Oliveira ${ }^{1}$ e lonizete Garcia da Silva ${ }^{2}$
}

\begin{abstract}
Resumo O efeito do extrato bruto etanólico da casca do caule da Magonia pubescens foi analisado no tubo digestivo de larvas de terceiro estádio do Aedes aegypti. Diferentes tempos de exposição $(2,4,6,8,10,12 e$ 13 horas) foram utilizados com a finalidade de verificar, de forma progressiva, as alterações morfológicas. Os efeitos tóxicos do e.b.e. foram evidenciados, principalmente, ao nível do mesêntero, íniciando-se na região anterior e, estendendo-se para a região posterior. As principais alterações observadas incluíram, destruição total ou parcial das células, alta vacuolização citoplasmática, aumento do espaço subperitrófico, hipertrofia das células e, aparente estratificação epitelial. Essas alterações iniciaram-se após 4 horas de tratamento, sendo que, diferentes graus de destruição foram observados de acordo com o aumento do tempo de exposição ao e.b.e. e com a parte do mesêntero analisado. Este trabalho evidencia o mecanismo de ação do e.b.e. da M. pubescens, ampliando o seu potencial de utilização no controle do A. aegypti.
\end{abstract}

Palavras-chaves: Aedes aegypti. Magonia pubescens. Tubo digestivo. Larva. Toxicidade.

\begin{abstract}
Crude ethanol extracted from Magonia pubescens trunks was utilized to prove its effect in the intestinal tract of Aedes aegypti $3^{r d}$ instar larvae. Exposure times (2, 4, 6, 8, 10,12, and 13 hours) were tested to verify when the morphological alterations begin to occur, in the intestinal tract of the larvae. The toxic effect of the extract was mainly in the midgut, beginning at the anterior midgut and followed through to posterior midgut. The main alterations observed were partial or total cell destruction, high citoplasmatic vacuolization, increase of subperitrophic space, cell hypertrophy and the epithelium did not maintain its monolayer appearance. The alterations began after four hours of exposure to M. pubescens extract. Observations of tissue sections from larvae treated for different lengths of time revealed a wide variation in the degree of damage between exposure periods and midgut larvae region. The present study provides evidence regarding the mode of action of the $\mathrm{M}$. pubescens extract and suggests its potential utilization as a larvicide to control Aedes aegypti mosquito.
\end{abstract}

Key-words: Aedes aegypti. Magonia pubescens. Midgut. Larvae. Toxicity.

Durante anos e, ainda hoje, a principal ação no controle do Aedes aegypti, baseia-se no uso de inseticidas químicos sintéticos ${ }^{151621}$. Estes compostos têm a vantagem de promoverem ação rápida e eficiente no combate, entretanto, apresentam desvantagens como a alta toxicidade para mamíferos e o meio ambiente. Desta forma, vários outros métodos de controle, com baixa toxicidade, vêm sendo avaliados, dentre esses, encontram-se os de origem botânica ${ }^{4714192325}$. Apesar dos estudos a respeito da atividade larvicida de plantas, não existe trabalhos que indicam a ação desses compostos para $A$. aegypti, através de análises morfológicas.

A planta Magonia pubescens (Sapindaceae), característica do Cerrado da região Centro-Oeste, vem sendo estudada e tem apresentado atividade larvicida, através de bioensaios, para todas as fases do desenvolvimento do $A$. aegypt ${ }^{25}$. Contudo, o mecanismo de ação ainda permanecia desconhecido. Assim, este trabalho teve a finalidade de elucidar esse aspecto através de estudos histológicos e histoquímicos.

\footnotetext{
1. Departamento de Morfologia do Instituto de Ciências Biológicas da Universidade Federal de Goiás, Goiânia, GO. 2. Laboratório de Biologia e Fisiologia de Insetos e Xenodiagnóstico do Instituto de Patologia Tropical e Saúde Pública da Universidade Federal de Goiás, Goiânia, GO.

Apoio Financeiro: CNPq processo 521136/98-9, OPAS, FUNAPE.

Endereço para correspondência: Dr. Ionizete Garcia da Silva. Dept ${ }^{\circ}$ de Microbiologia, Imunologia, Parasitologia e Patologia/IPTSP/UFG. Caixa Postal 131, 74001-970 Goiânia, GO.

Tel: 62 209-6128; Fax: 62 261-2077.

e-mail: ionizete@iptsp.ufg.br ou walqui@icb2.ufg.br

Recebido para publicação em 26/9/2001.
} 


\section{MATERIAL E MÉTODOS}

Larvas de $3^{\circ}$ estádio do $A$. aegypti foram criadas numa câmara biológica climatizada com temperatura de $28 \pm 1^{\circ} \mathrm{C}$, umidade relativa de $80 \pm 5 \%$ e fotofase aproximadamente de 12 horas $^{24}$.

O extrato bruto etanólico (e.b.e.) da casca do caule da $M$. pubescens foi utilizado na concentração letal $\left(\mathrm{CL}_{100}\right)$, equivalente a $230 \mathrm{mg} / \mathrm{L}$ de água destilada ${ }^{25}$. Essa solução foi deixada em repouso por algumas horas para sedimentação da espuma formada, posteriormente, distribuía-se $25 \mathrm{ml}$ dessa solução em cada um dos 20 frascos utilizados. Para o controle utilizaram-se frascos com água destilada, sendo distribuída nos 20 frascos com o mesmo volume da solução do extrato.

Colocaram-se seis larvas em cada frasco com a solução do e.b.e., e a mesma quantidade de larvas em água destilada para o controle. Cada experimento foi dividido em quatro grupos, relacionados da seguinte maneira: grupo 1 - larvas na solução do e.b.e., com alimento; grupo 2 - larvas na solução do e.b.e., sem alimento; grupo 3 - controle com alimento e grupo 4 - controle sem alimento. $\mathrm{O}$ alimento utilizado foi ração para gato finamente triturada ${ }^{24}$. As larvas permaneciam na solução do e.b.e. por tempos variados, sendo coletadas em intervalos de 2, 4, 6, 8, 10, 12 e, com 13 horas, quando ocorria a mortalidade total. Esses intervalos foram utilizados para verificar os níveis de alterações morfológicas que ocorriam com o tempo de exposição ao extrato da planta.

As larvas coletadas foram imediatamente fixadas em $2 \%$ glutaraldeído, $2 \%$ paraformaldeído, 3\% sacarose em tampão cacodilato de sódio $0,1 \mathrm{M} \mathrm{pH} 7,2$ pelo período de 2 horas, desidratadas e, embebidas e incluídas em resina (Leica Historesin Embedding Kit). Os blocos de resina foram cortados com espessura de $3 \mu \mathrm{m}$ e corados segundo as técnicas de hematoxilina- eosina, xylidine Ponceau, azul de bromofenol, PAS e PAS/ferro coloidal5 613171820 , posteriormente, examinados e fotografados.

\section{RESULTADOS}

Foram reconhecidas três regiões no mesêntero das larvas controle de $A$. aegypti, denominadas de região anterior, mediana e posterior (Figura 1A). As células epiteliais da região anterior (Figura 1B), dispostas em uma única camada de células cilíndricas baixas, apresentaram citoplasma, evidenciando regiões mais e menos acidófilas. A superfície apical destas células evidenciaram uma delgada linha pouco corada representando uma fina borda em escova. A membrana peritrófica apresentou-se como uma fina membrana refringente a luz envolvendo todo o conteúdo alimentar.

$\mathrm{Na}$ região mediana do mesêntero, as células epiteliais apresentaram-se um pouco mais altas, mas com as mesmas características citoplasmáticas, entretanto, a borda em escova mostrou-se menos corada e um pouco mais espessada (Figura 1C). Além das células epiteliais cilíndricas, observou-se nesta região, a presença de algumas células com aspecto mais esférico e globuloso, semelhante à células caliciformes, que se mostraram palidamente coradas com a técnica de HE. O núcleo celular em ambas regiões apresentou-se, esférico e basal, exibiu áreas de hetero e eucromatina bem evidentes, com nucléolo único e esférico, quando presente, indicando a alta atividade da célula.

As células da região posterior do mesêntero apresentaram-se um pouco mais baixas, sendo que algumas células evidenciaram o citoplasma com intensa basofilia, núcleo basal e esférico, com cromatina condensada, enquanto que, outras células apresentaram citoplasma menos corado, com núcleo evidenciando as mesmas características morfológicas observadas nas outras regiões (Figura 1D). Apesar destas diferenças, todas as células desta região apresentaram o citoplasma com aspecto rendado, cheio de reentrâncias e, com uma espessa borda em escova na superfície apical.

A intensa atividade secretora das células do mesêntero é evidenciada na Figura 1E, onde observouse a intensa basofilia e grande quantidade de vesículas de secreções na superfície apical destas células.

No que se refere as larvas que foram submetidas ao e.b.e. da M. pubescens, verificou-se que não houve diferenças entre os tratamentos com e sem alimento, nos tempos examinados. Assim as análises foram realizadas levando-se em consideração o tempo de exposição da larva ao e.b.e. da $M$. pubescens, independentemente da oferta ou não de alimento.

As principais alterações observadas com o tratamento com o e.b.e. foram a nível do mesêntero e, as primeiras mudanças nas células epiteliais foram visualizadas com 4 horas de tratamento. A Figura 2, mostra em corte longitudinal, a região anterior e mediana do mesêntero, de larvas mantidas por 4 horas na solução do e.b.e., evidenciando uma grande destruição celular a nível da região anterior e um estado de preservação das células na região mediana. A maioria das células da região anterior, apresentaram o citoplasma cheio de pequenas estruturas esféricas, semelhantes a vacúolos e núcleo pálido, corado em róseo, mostrando cromatina descondensada e nucléolo evidente, enquanto que, outras poucas células, aparentemente localizadas na base do epitélio, ainda apresentaram o aspecto típico encontrado nas células do controle, em contraste com a região mediana, que ainda apresentaram as células preservadas, com citoplasma íntegro apenas com raros vacúolos e núcleo com aspecto normal. A membrana peritrófica apresentou-se como uma fina camada intensamente acidófila, limitando as células epiteliais dos restos de 

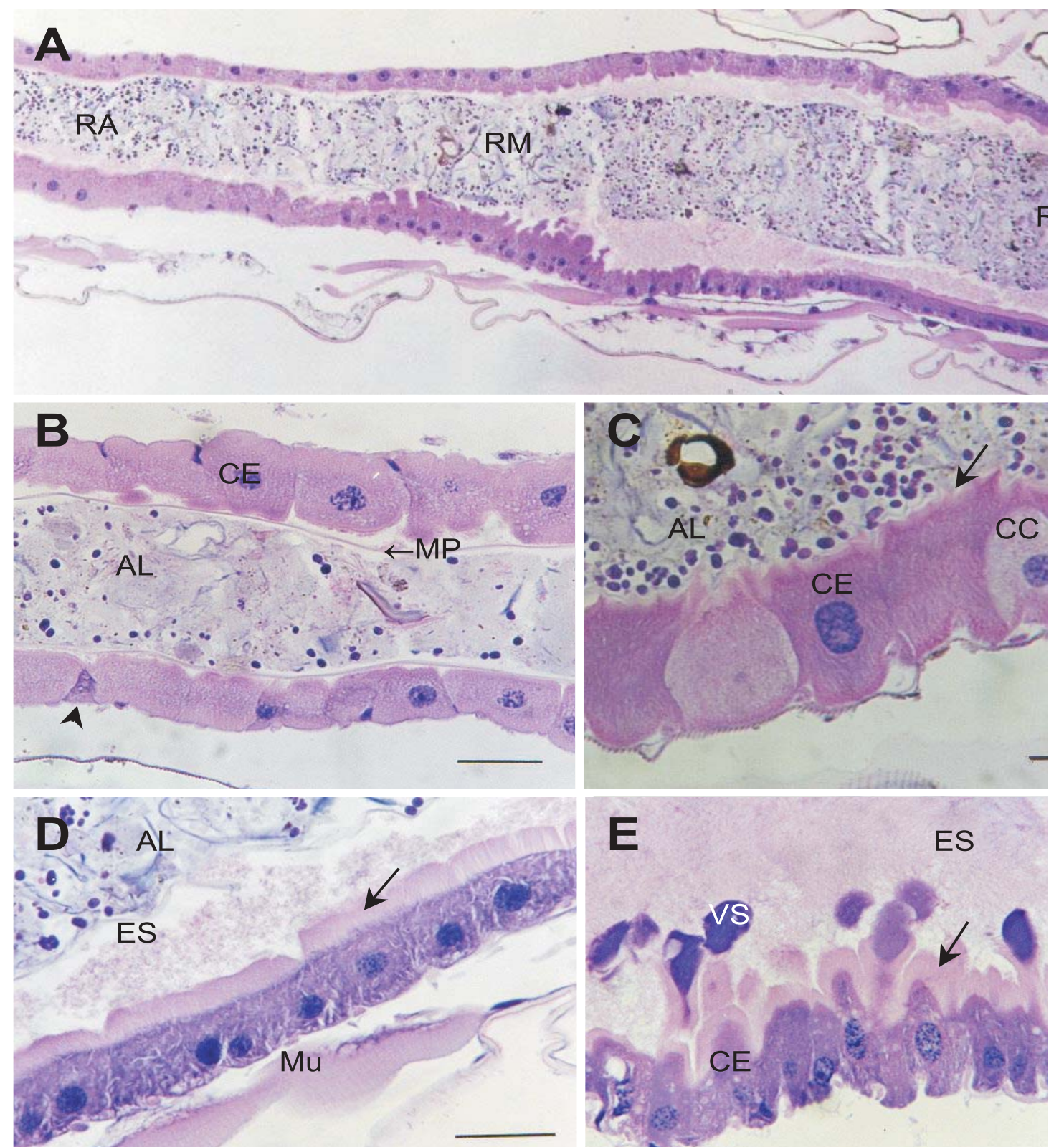

Figura 1 - Fotomicrografias do intestino médio ou mesêntero de larvas de $3^{\circ}$ estádio de Aedes aegypti controle, coradas com HE. A. Vista geral. 100X. Bar=10um. B. Região anterior. 400X. C. Região mediana. 500X. D. região posterior. 500X. E. Região posterior evidenciando grande atividade secretora. 500X. Bar $=3 \mu \mathrm{m}$. Região anterior (RA), Região mediana (RM), Região posterior (RP), célula epitelial (CE), membrana peritrófica (MP), célula clara (CC), espaço subperitrofico (ES), vesícula secretora (VS), borda em escova (seta), célula regenerativa (ponta de seta), muscular (Mu), alimento (AL).

alimento ainda presente no interior do tubo digestivo. Esse aspecto da região anterior foi marcadamente evidenciado em todos os tempos de tratamento após 4 horas de exposição, sendo que, tais mudanças apresentaram-se mais intensas de acordo com o aumento do tempo de exposição ao e.b.e., notando-se principalmente o aumento da quantidade de vacúolos e ausência dos limites citoplasmáticos. A partir de 6 horas de tratamento pode-se notar o aspecto estratificação epitelial desta região, evidenciando algumas células pequenas e basais, provavelmente na tentativa de repor as células epiteliais que foram destruídas (Figura 3).

Com 8 horas de tratamento há evidências da passagem das alterações morfológicas observadas na 


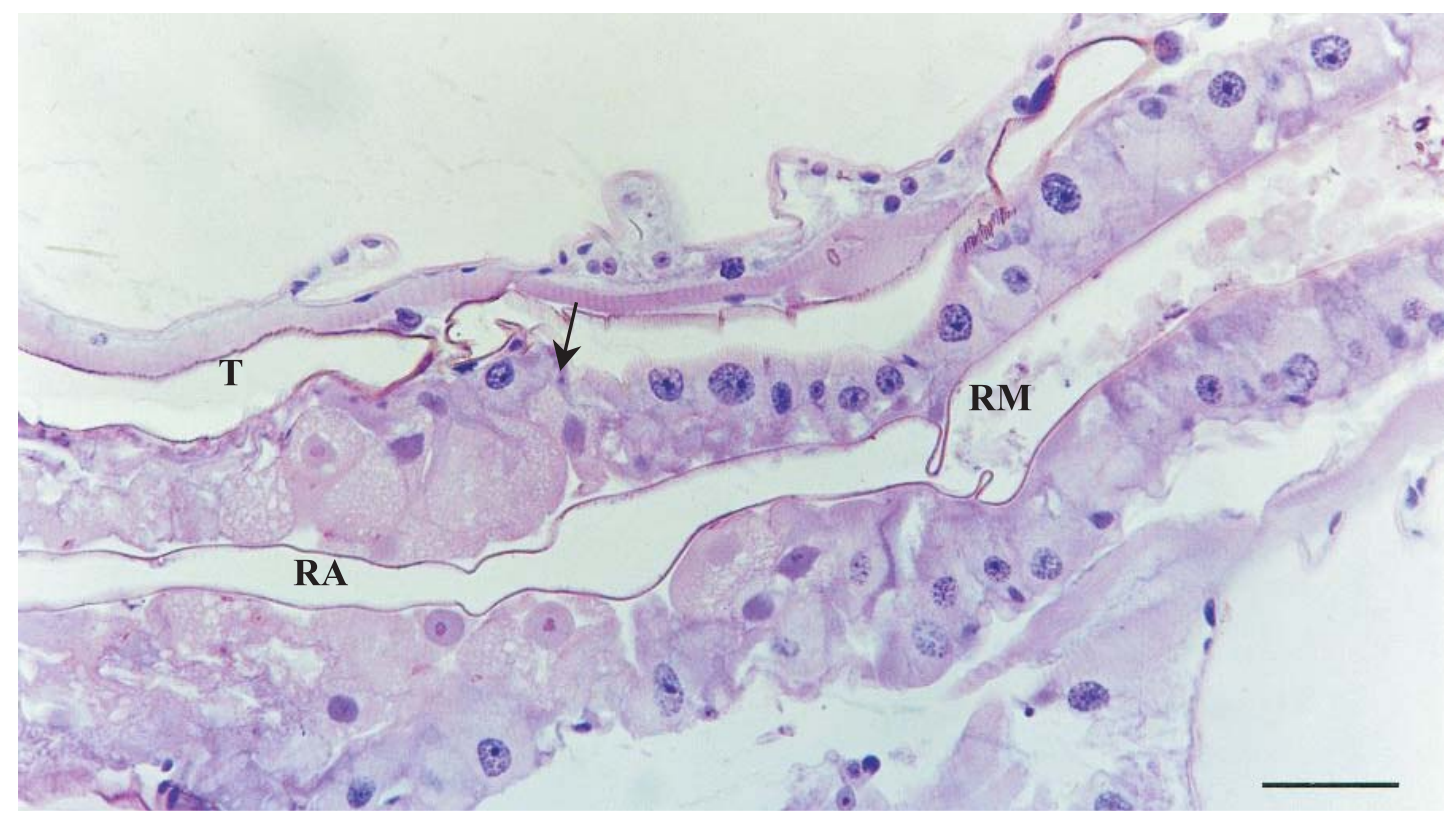

Figura 2 - Fotomicrografia do mesêntero de larvas de $3^{\circ}$ estádio do Aedes aegypti tratadas por 4 horas, sem alimento, com o e.b.e. da Magonia pubescens evidenciando a transição (seta) entre a regiao anterior (RA) e mediana (RM). Traquéia (T). 250X. Bar=5 $\mu \mathrm{m}$. HE.

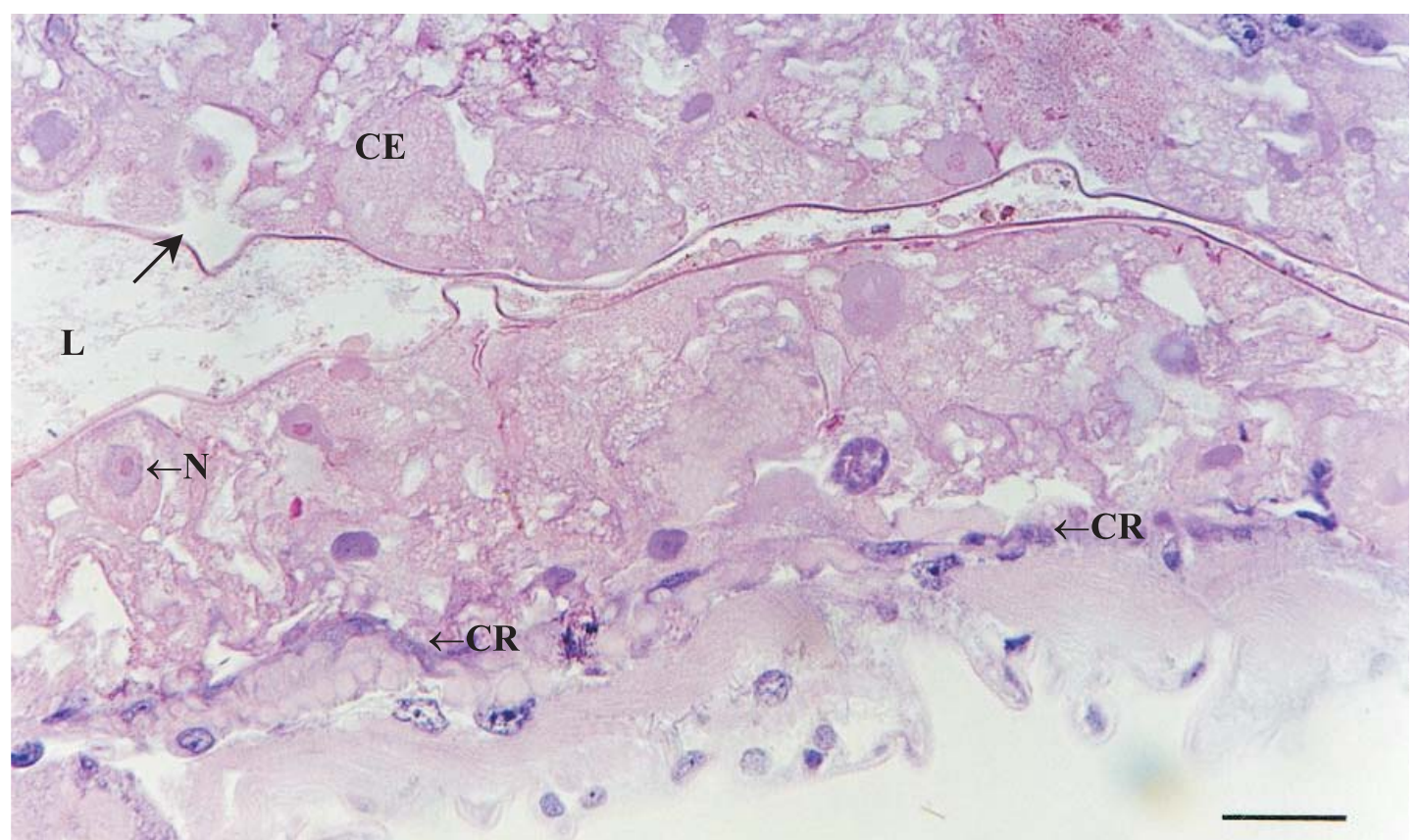

Figura 3 - Região anterior do mesêntero de larvas de Aedes aegypti tratadas por 6 horas, com alimento, com o

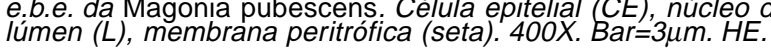


região anterior para a região mediana, indicando o potencial gradativo de destruição (Figura 4). As células da região mediana apresentaram-se cilíndricas altas e bastante vacuolizadas, começando a adquirir o aspecto morfológico de destruição encontrado na região anterior e, posteriormente, essas células mostraram-se mais baixas, com limites celulares bem definidos e, mais preservadas quando comparadas com as células da região anterior, contudo, evidenciaram vários sinais de destruição celular, como a presença de grande quantidade de vacúolos. A membrana peritrófica mostrou-se na região anterior, como uma camada marcante e evidente, bastante acidófila, apresentandose deslocada do ápice da célula, limitando um espesso espaço subperitrófico e, na região mediana, localizouse bem próximo a borda em escova das células epiteliais, delimitando um espaço subperitrófico mais escasso e preenchido por substâncias (Figura 4).

A partir de 10 horas de tratamento observou-se, além das alterações relatadas, o aumento do espaço subperitrófico com acúmulo de material acidófilo na região mediana (Figura 5).

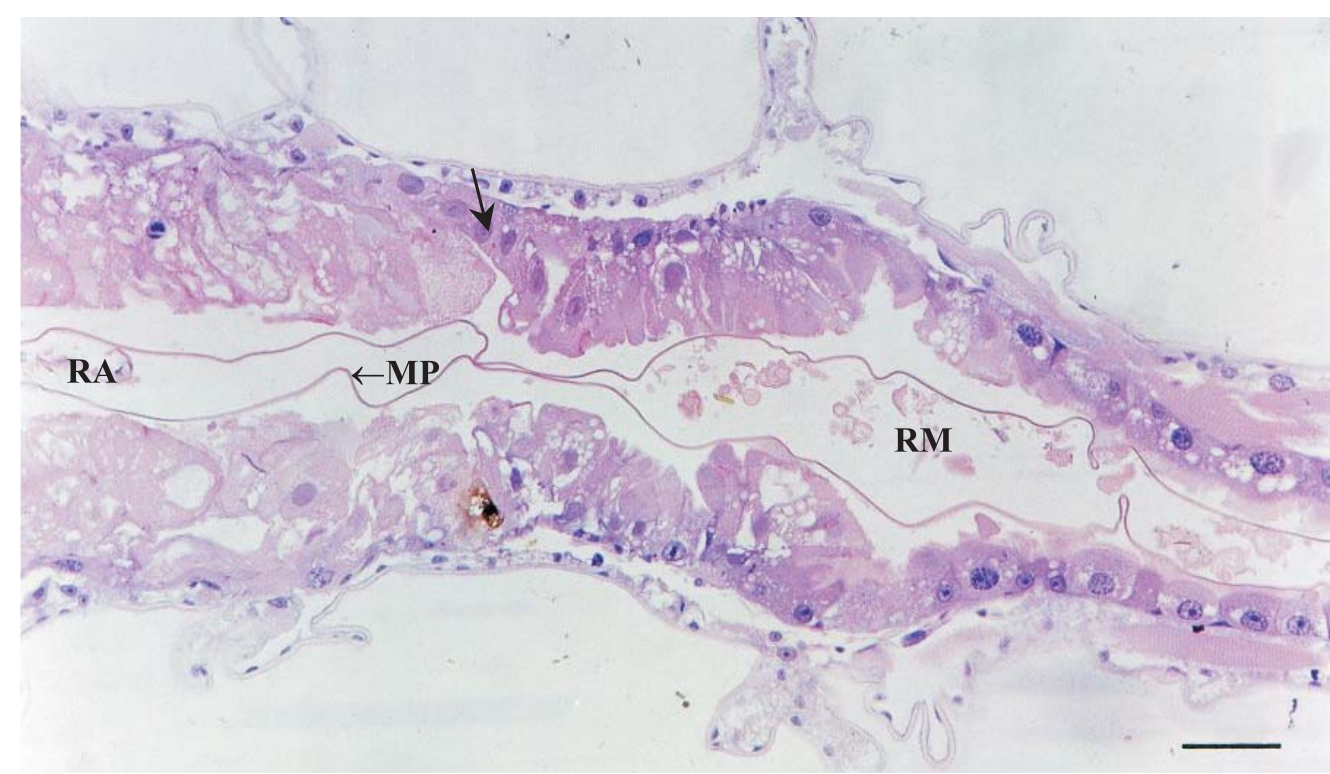

Figura 4 - Transição (seta) entre a região anterior (RA) e mediana (RM) do mesêntero de larvas de $3^{\circ}$ estádio de Aedes aegypti tratadas por 8 horas com o e.b.e. da Magonia pubescens. Membrana peritrófica $(M P)$, células epiteliais (CE). 200X. Bar $=5 \mu \mathrm{m}$. HE.

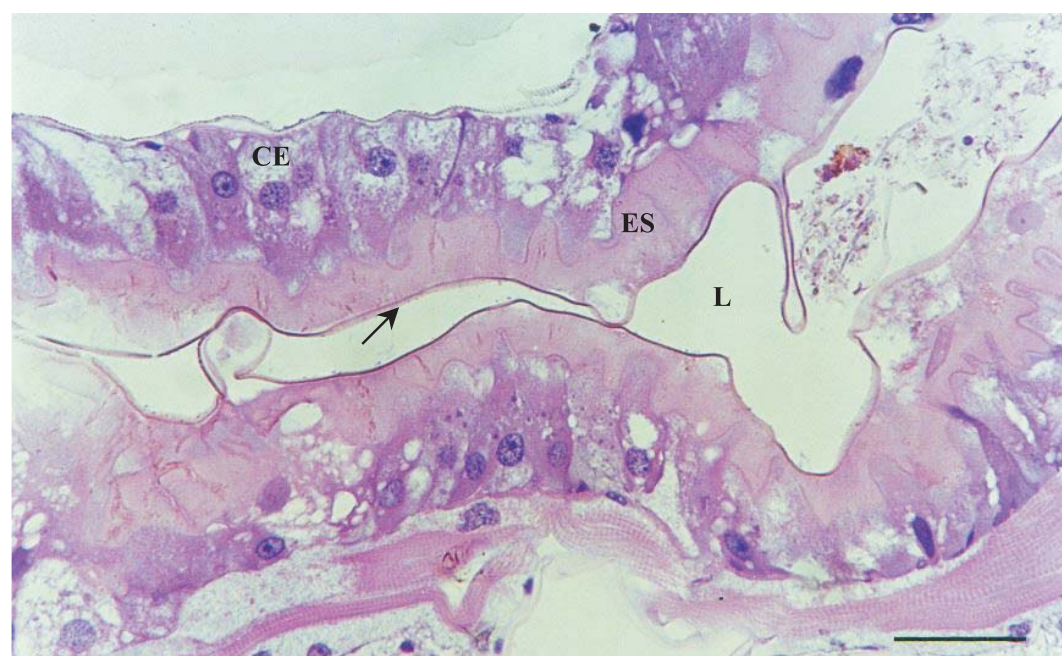

Figura 5 - Detalhe da região mediana do mesêntero de larvas de $3^{\circ}$ estádio de Aedes aegypti submetidas ao e.b.e. da Magonia pubescens, por 12 horas, sem alimento. Espaço subperitrófico (ES), células epiteliais (CE), membrana peritrófica

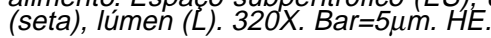


Com 13 horas na solução do e.b.e. verificou-se que a região anterior do intestino médio, apresentou-se completamente destruída e essa destruição progrediu para toda a região mediana e posterior (Figura 6). As células do epitélio, aparentemente estratificado, pelo aumento do número de células de substituição, apresentou um aspecto gradativo de destruição, indicando que, as células cilíndricas passam por diferentes estágios antes da lise, quando se rompem na superfície do epitélio e liberam o restante do seu citoplasma no espaço subperitrófico (Figura 7) Desta forma, inicialmente estas células com aparência globosa, apresentaram-se situadas na região basal do epitélio (1). Em seguida, adquiriram o aspecto de gota, com a superfície apical celular afilada, indicando que está iniciando um processo de eliminação do seu conteúdo, ou de um produto de secreção (2). Finalmente, as células localizaram-se próximo ao espaço subperitrófico (3), rompendo-se na superfície livre do epitélio (4). Observou-se semelhanças, quanto ao aspecto e coloração, entre o conteúdo citoplasmático destas células e o conteúdo existente no espaço subperitrófico. As células cilíndricas do epitélio, apresentaram-se cobertas por uma espessa borda em escova e, o espaço subperitrófico apresentou-se como uma camada espessada. Talvez por este fato, este seja ocupado por uma substância com características de coloração semelhantes a do citoplasma celular. Enquanto esse processo ocorria novas células epiteliais se diferenciavam a partir das células regenerativas, ocupando o espaço pertencente às primeiras.

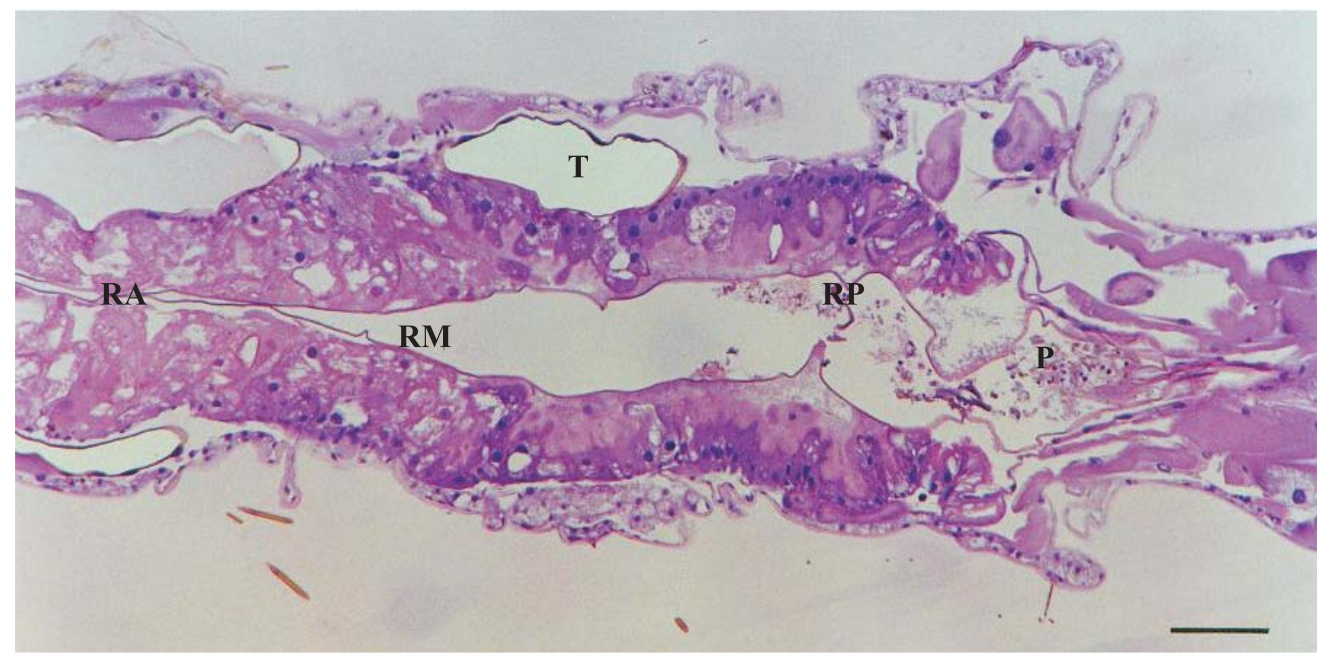

Figura 6 - Transição entre a região anterior $(R A)$ mediana $(R M)$ e posterior $(R P)$ do mesêntero de larvas de $3^{\circ}$ estádio do Aedes aegypti mantidas por 13 horas, com alimento, na solução do e.b.e. da Magonia

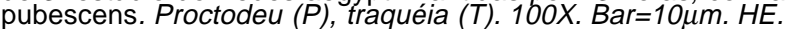

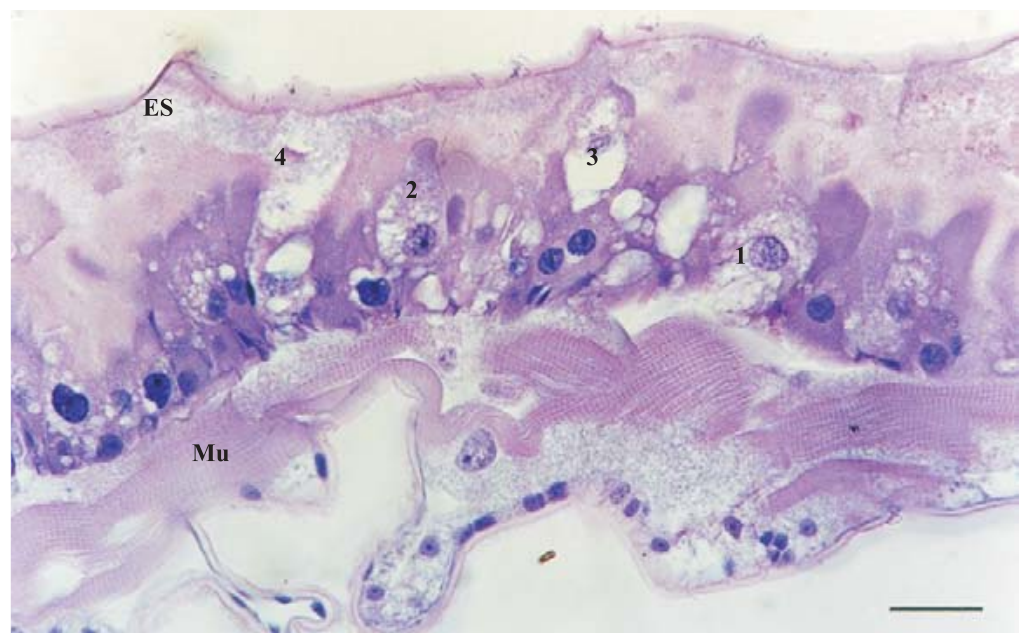

Figura 7 - Detalhe da região mediana do mesêntero de larvas de $3^{\circ}$ estádio do Aedes aegypti mantidas por 13 horas, com alimento, na solução do e.b.e. da M agonia pubescens, evidenciando as várias etapas da lise das células epiteliais

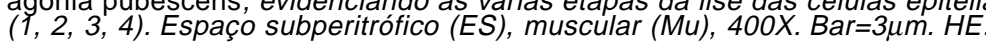


Os testes histoquímicos realizados visaram determinar a natureza química dos componentes das células claras e vesículas secretoras presentes no epitélio de revestimento do intestino médio do controle, bem como, do conteúdo presente no espaço subperitrófico e membrana peritrófica, localizado no revestimento intestinal de larvas que foram expostas ao e.b.e. da M. pubescens. Os resultados dos testes histoquímicos são apresentados nas Tabelas 1 e 2 .

Tabela 1 - Resultados das reações histoquímicas sobre larvas de Aedes aegypti no grupo controle.

\begin{tabular}{lcccc}
\hline & PAS & PAS/ferro coloidal & Azul de bromofenol & Xylidine ponceau \\
\hline Ápice celular & + & +++ & + & + \\
Vesículas de secreção & +++ & +++++++ & +++ & ++ \\
Células claras & - & - & - & - \\
Células cilíndricas & + & ++ & +++++++ & +++++++ \\
\hline$++++/+++$ alta positividade; ++ média positividade; + fraca positividade; - negativo.
\end{tabular}

Tabela 2 - Resultados das reações histoquímicas sobre larvas de Aedes aegypti no grupo tratado

\begin{tabular}{lcccc} 
& PAS & PAS/ferro coloidal & Azul de bromofenol & Xylidine ponceau \\
\hline Espaço subperitrófico & $+/++$ & ++ & +++ & ++ \\
Membrana peritrófica & ++ & ++++ & +++++++ & $+++/+++$ \\
\hline
\end{tabular}

++++ / +++ alta positividade; ++ média positividade; + fraca positividade; - negativo.

\section{DISCUSSÃO}

Nas larvas controle de $A$. aegypti, todas as regiões do mesêntero apresentaram-se revestidas por uma única camada de células com características cilíndricas com as mesmas características descritas para os insetos em geral ${ }^{26}$ e para o $A$. aegypti ${ }^{12}$. Entretanto, encontramos na região mediana do mesêntero, algumas células cilíndricas fracamente coradas por HE (células claras), não descritas por estes autores (Figura 1C). Inicialmente questionou-se quais eram estas células e qual sua funcionalidade, visto que, as células globet, também com características mais claras e com função mucosa, são encontradas apenas no revestimento epitelial do intestino de Lepdoptera, Ephemenoptera, Plecoptera e Trichoptera ${ }^{326}$ e, dados relacionados a estas células em larvas de $A$. aegypti não foram encontrados na literatura. Por este fato, foram realizadas reações histoquímicas (Tabela 1), para tentar identificar as características funcionais básicas destas células, bastante diferenciadas e não relatadas nos estudos de microscopia óptica de larvas de $A$. aegypti. Os testes histoquímicos realizados revelaram-se negativos para todas as reações. Células endócrinas localizadas no mesêntero dos insetos adultos em geral, são caracterizadas por apresentarem citoplasma claro $^{10}$. Foram relatados ainda a presença de células claras, possivelmente com função endócrina, localizadas somente na região do mesêntero de adultos de Culicidae $^{8}$ e, células pequenas e basais, espalhadas entre as células digestivas de adultos de $A$. aegypti . Não foram encontrados relatos da existência de células endócrinas presentes no tubo digestivo de larvas, nem dados concretos que indiquem a natureza endócrina destas células claras. Supõe-se que estas células sejam diferenciadas, por sua atividade ou função, e não se pode portanto, descartar a possibilidade de uma natureza endócrina, contudo, essa confirmação só poderá ser conseguida com estudos mais específicos como marcação por imunocitoquímica.

Nenhuma referência foi encontrada com relação ao processo de secreção das células observado na região mediana e posterior do mesêntero de larvas de A. aegypti. Essas observações mostraram a existência de grandes vesículas basofílicas liberadas por essas células (Figura 1E) revelando sua grande atividade secretora. A natureza química destas vesículas foi investigada através de algumas reações histoquímicas, mostrados na Tabela 1. Esses dados evidenciaram intensa positividade para todas as reações, indicando a presença de mucopolissacarídeos neutros e, a existência de compostos protéicos nestas vesículas. Produtos de secreção, como enzimas, são realmente liberados pelas células do mesêntero, visto que, a função desta região está primordialmente ligada a produção de líquidos contendo enzimas digestivas e a absorção de produtos da digestão ${ }^{1026}$, apontando para a natureza protéica encontrada nestas vesículas.

Geralmente, os efeitos tóxicos do e.b.e. da $M$. pubescens sobre o $A$. aegypti foram observados primariamente na região anterior do mesêntero. Uma progressão dos danos ocorridos nas células da região posterior do mesêntero e cecos gástricos de larvas de Simulium vittatum infectadas pelo $B$. thuringiensis, evidenciaram que a região anterior com exceção dos cecos e região mediana inafetadas na maioria das larvas ${ }^{11}$, enquanto que, alterações histopatológicas causadas pelo $B$. thuringiensis israelensis, foram mais evidenciadas em nível da região anterior e posterior do mesêntero ${ }^{12}$. Entretanto, em nossos estudos, os efeitos deletérios do e.b.e. da $M$. pubescens se direciona continuamente da região anterior para as regiões mediana e posterior do mesêntero, evidenciando uma 
crescente e contínua passagem dos danos ao longo do tubo digestivo. Estudos indicam que várias alterações ocorrem apenas nas células da região posterior do mesêntero de Culiseta incidens infectadas com o B. sphaericus ${ }^{9}$, entretanto, dados relacionados a alterações do mesêntero frente a larvicidas botânicos não foram encontrados na literatura.

As alterações deletérias nas células do mesêntero provocadas pelo e.b.e. incluíram várias mudanças histopatológicas como a destruição total ou parcial das células, alta vacuolização do citoplasma, aumento do espaço subperitrófico com acúmulo de material acidófilo no seu interior, aparente aumento do número de camadas do epitélio, aumento da espessura da membrana peritrófica e hipertrofia das células. Provavelmente, o aparente aumento do número de camadas do epitélio resultou da proliferação de células regenerativas, que originaram novas células. Entretanto, notou-se que essas células epiteliais recém formadas, também sofrem ação tóxica do e.b.e. e, se alteram, podendo evidenciar no epitélio um aspecto de descamação.

Várias destas alterações vão de encontro as observações histológicas visualizadas principalmente na região anterior e posterior do mesêntero causadas por agentes de controle biológico ${ }^{111}{ }^{12}$, dentre elas, a separação das células epiteliais da membrana basal, desintegração da borda em escova, completos danos na membrana peritrófica, hipersecreção pelas células epiteliais, lise celular, destruição completa da camada epitelial, vacuolização celular. Por outro lado, estudos da histopatologia de larvas de $A$. aegypti parasitadas por Reesimermis nielseni revelaram poucas diferenças entre os tecidos controles e infectados, sendo que nenhuma alteração foi encontrada nas células do mesêntero ${ }^{1}$.

Tentativas foram feitas para seguir os danos causados pelo e.b.e. no mesêntero das larvas de A. aegypti. Essas, foram alcançadas por observações comparativas de larvas tratadas em diferentes tempos de exposição ao e.b.e., com larvas controle. Há evidências de um aumento gradual das transformações celulares observadas a microscopia óptica, quando se aumenta gradualmente o tempo de exposição da larva ao e.b.e., até a destruição celular total indicada pela morte da mesma. Alterações foram encontradas em nível de todo tubo digestivo, nas lâminas referentes às larvas submetidas ao e.b.e., quando estas foram comparadas com as lâminas controle. Não houve diferenças nas amostras tratadas com alimento e sem alimento, sugerindo que, o provável processo de absorção das toxinas do e.b.e., seja realizado em nível do intestino, pela ingestão de partículas do e.b.e. presentes na água e/ou pelo tegumento da larva. As destruições celulares se iniciaram ao nível da região anterior do mesêntero, se difundindo gradativamente por todas as outras porções, indicando um processo gradual de destruição.

Tentativas de identificar alguma alteração na natureza química das células do mesêntero de larvas tratadas, foi verificada pelo uso de reações histoquímicas nos cortes que evidenciaram maiores alterações e efeitos mais pronunciados da toxicidade do e.b.e. da M. pubescens, ou seja, em cortes do mesêntero de larvas tratadas pelo período de 12 horas. Estas apresentaram nos cortes corados por HE o espaço subperitrófico espessado e preenchido por uma substância desconhecida. Os testes positivos para todas as reações no espaço subperitrófico de larvas tratadas e citoplasma de células íntegras, indicam que o conteúdo de ambos apresentam a mesma natureza química, apontando para a idéia de que o restante do citoplasma celular seja eliminado para o espaço subperitrófico durante o tratamento com o e.b.e.

A membrana peritrófica apresentou-se mais espessada no tubo digestivo de larvas tratadas do que de larvas controle (Figuras 1B e 5), sendo bem evidenciada nos cortes submetidos as reações histoquímicas. A intensa positividade para todas as reações realizadas (Tabelas 1 e 2 ), provavelmente se deve ao fato dessa estrutura conter quitina e proteína ${ }^{322}$. Seu espessamento pode ser considerado um mecanismo de defesa da larva, visto que, uma das principais funções desta membrana é a proteção das células epiteliais, contra a ação mecânica do alimento, podendo ainda, agir como uma barreira para invasão de microorganismos ingeridos e patógenos ${ }^{22} 27$. Desta forma, a membrana peritrófica caracterizada nos cortes histológicos como uma linha que separa o epitélio do alimento e, visualizada em alguns cortes histológicos de larvas tratadas, como uma bainha mais espessada, indica que, esta pode ser uma forma de proteção e/ou defesa, visto que seu espessamento tenta impedir a passagem do e.b.e. para o espaço subperitrófico e conseqüentemente, entrar em contato com as células do mesêntero, ligadas com o processo de absorção. Assim, em função do uso do e.b.e. da M. pubescens, a larva produziria uma membrana mais densa.

\section{AGRADECIMENTOS}

Os autores agradecem ao histotécnico Otávio Cavalcante Barros, pela grande prestabilidade e auxílio no preparo dos cortes histológicos em resina.

\section{REFERÊNCIAS BIBLIOGRÁFICAS}

1. Bailey $\mathrm{CH}$, Gordon R. Histopathology of Aedes aegypti (Diptera: Culicidae) larvae parasited by Reesimermis nielseni (Nematoda: Mermithidae). Journal of Invertebrate Pathology 23:435-411, 1973.
2. Brown MR, Raikhel AS, Lea AO. Ultrastructure of midgut endocrine cells in the adult mosquito, Aedes aegypti. Tissue \& Cell 17:709-721, 1985. 
3. Chapman RF. The Insects: Structure and Function. Hodder and Stoughton, London, 1982.

4. Dharmshaktu NS, Prabhakaran PK, Menon PK. Laboratory study on the mosquito larvicidal properties of leaf and seed extract of the plant Agave americana. Journal of Tropical Medicine and Hygiene 90:79-82, 1987.

5. Filipe MI, Lake BD. Histochemistry in Pathology. Churchill Livingston, New York 1983.

6. Gabe M. Histological Techniques. Masson, Paris. 1976.

7. Green MM, Singer JM, Sutherland DJ, Hibben CR. Larvicidal activity of Tagetes minuta (Marigold) toward Aedes aegypti. Journal of American Mosquito Control Association 7:282-286, 1991.

8. Hecker H. Structure and function of midgut epithelial cells in Culicidae mosquitoes (Insecta, Diptera). Cell and Tissue Research 184:321-341, 1977.

9. Kellen WR, Clark TB, Lindegren JE, Ho BC, Rogoff MH, Singer S. Bacillus sphaericus Neide as a pathogen of mosquitoes. Journal of Invertebrate Pathology 7:442-448, 1965.

10. Kerhut GA, Gilbert LI. Comprehensive Insect Physiology, Biochemistry and Pharmacology. Pergamom Press, London 1985.

11. Lacey LA, Federici BA. Pathogenesis and midgut histopathology of Bacillus thuringiensis in Simulium vittatum (Diptera: Simuliidae). Journal of Invertebrate Pathology 33:171-182, 1979.

12. Lahkim-Tsror L, Pascar-Gluzman C, Margalit J, Barak Z. Larvicidal activity of Bacillus thuringiensis subsp. Israelensis, serovar $\mathrm{H} 14$ in Aedes aegypti: Histopathological studies. Journal of Invertebrate Pathology 41:104-116, 1983.

13. Luna LG. Manual of Histologic Staining Methods of the Armed Forces Institute of Pathology. McGraw-Hill, New York, 1968.

14. Macêdo ME, Consoli RAGB, Grandi TSM, Anjos AMG, Oliveira ABO, Mendes NM, Queiróz RO, Zani CL. Screening of Asteraceae (Compositae) plant extracts for larvicidal activity against Aedes fluviatilis (Diptera: Culicidae). Memórias do Instituto Oswaldo Cruz 92:565-570, 1997.

15. Marcoris MLG, Camargo MF, Silva IG, Takaku L, Andrighetti MT. Modificação da suscetibilidade de Aedes (Stegomyia) aegypti ao Temephos. Revista de Patologia Tropical 24:31-40, 1995.
16. Matsumura F, Brown AWA. Studies on organophosphorustolerance in Aedes aegypti. Mosquito News. 23:26-31, 1963.

17. Melo MLS, Vidal BC. Práticas de Biologia Celular. Edgar Blücher Ltda, São Paulo, 1980.

18. Pearse AGE. Histochemistry: Theoretical and Applied. J \& A Churchill Ltd., London, 1961.

19. Pizarro APB, Filho AMO, Parente JP, Melo MTV, Santos CE, Lima PRO. Aproveitamento do resíduo da indústria do sisal no controle de larvas de mosquitos. Revista Sociedade Brasileira de Medicina Tropical 32:23-29, 1999.

20. Prophet EB, Mills B, Arrington JB, Sabin LH. Laboratory Methods in Histotechnology: American Registry of Pathology, Washington, 1992.

21. Rathor HR, Wood RJ. Effect of selection for dichlorodiphenyltrichlorethane (DDT) resistance on the uptake and breakdown of DDT in Aedes aegypti L. Canadian Journal of Genetic and Cytology 27:23-28, 1985.

22. Richards AG, Richards PA. The peritrophic membranes of insects. Annual Review of Entomology 22:219-240, 1977.

23. Schwartz AM, Paskewitz SM, Orth AP, Tesch MJ, Toong YC, Goodman WG. The lethal effects of Cyperus iria on Aedes aegypti. Journal of American Mosquito Control Association 14:78-82, 1998.

24. Silva HHG, Silva IG, Lira KS. Metodologia de criação, manutenção de adultos e estocagem de ovos Aedes aegypti (Linnaeus, 1762), em laboratório. Revista de Patologia Tropical 27:53-63, 1998.

25. Silva IG, Santos AH, Ferri PH, Alves RBN, Melo RL, Peixoto L, Silva HHG, Elias CN, Isac E, Lira KS, Camargo MF. Ação larvicida de extrato bruto etanólico de Magonia pubescens St. Hil. (tinguí do cerrado) sobre o Aedes aegypti (Lin) em laboratório. Revista de Patologia Tropical 25:51-59, 1996.

26. Snodgrass RE. Principles of Insect Morphology. McGraw-Hill Book Company, New York, 1935.

27. Zhuzhikov DP. Permeability of the peritrophic membrane in the larvae of Aedes aegypti. Journal of Insect Physiology 16:11931202, 1970. 